\title{
Süstalinable Chemistry\& Engineering

\section{Sustainable Production of Carbon Fiber: Effect of Cross-Linking in Wool Fiber on Carbon Yields and Morphologies of Derived Carbon Fiber}

\author{
Mohammad M. Hassan, ${ }^{*}{ }^{\dagger}$ Linda Schiermeister, ${ }^{\ddagger}$ and Mark P. Staiger ${ }^{\ddagger}$, \\ ${ }^{\dagger}$ Food \& Bio-based Products Group, AgResearch Ltd., Private Bag 4749, Christchurch 8140, New Zealand \\ ${ }^{\ddagger}$ MacDiarmid Institute for Advanced Materials and Nanotechnology, Department of Mechanical Engineering, University of \\ Canterbury, Private Bag 4800, Christchurch 8140, New Zealand \\ ${ }^{\S}$ The MacDiarmid Institute for Advanced Materials and Nanotechnology, P.O. Box 600, Kelburn, Wellington 6140, New Zealand
}

ABSTRACT: Currently, most of the carbon fibers are made from unsustainable fossil fuel-based precursors including high purity polyacrylonitrile (PAN) and pitch. High purity PAN is not only more expensive than wool fiber but also a limited quantity is produced because of global shortage of its monomer. In this work, various cross-linking pathways are explored as a means of altering the yield and tensile properties of carbon fiber derived from the carbonization of cross-linked wool fiber at 800 ${ }^{\circ} \mathrm{C}$ under nitrogen. A range of ionic and covalent-bond-forming cross-linking agents including bifunctional carboxylic acids (succinic acid and sebacic acid), a disulfonic acid (naphthalene

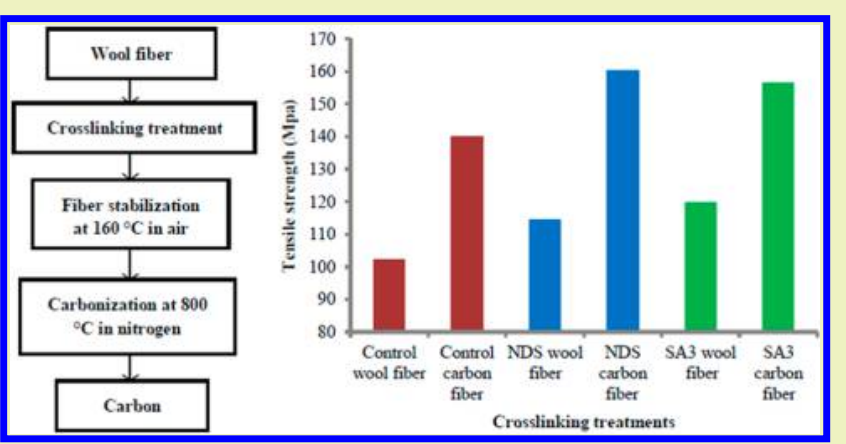
disulfonic acid), a dialdehyde (glyoxal), and dianhydrides (succinic anhydride and itaconic anhydride) was investigated. The resulting carbon fibers were characterized in terms of chemical composition, carbon yield, surface topology, crystal structure, hydrophilicity, and tensile properties. It was found that the carbon yield can be increased by $55 \%$ by using cross-linking treatments. Carbon fiber produced from untreated and crosslinked wool fibers all exhibited superhydrophilicity. Although the tensile strength of the resulting carbon fiber was relatively low in this preliminary study, the resulting fiber could have applications in the manufacturing of thermoplastic composite materials as low modulus filler.

KEYWORDS: Renewable carbon fiber precursor, Wool fiber, Cross-linking, Thermal properties, Surface analysis

\section{INTRODUCTION}

Carbon fiber is one of the most important technical fibers for use in advanced composite materials due to its unique chemical, electrical, and mechanical properties. ${ }^{1}$ The demand for this material is expected to increase by 4 -fold over the next decade as more uses are found for carbon fiber in consumer-grade products. ${ }^{2}$ Commercially, carbon fibers are mainly produced using a high purity polyacrylonitrile precursor fiber. The production of carbon fiber has been limited by the cost and shortage of high purity polyacrylonitrile fiber, accounting for approximately half the cost of production. Additionally, the fiber production process is complex and energy intensive due to the high temperatures required, further limiting the range of viable applications for carbon fiber. ${ }^{3}$ Carbon fibers are used in composites with a polymer matrix in developing lightweight materials ideally suited to applications where strength, stiffness, low density, damping, and fatigue resistance are critical requirements. The major barriers to widespread utilization of advanced carbon fiber composites in automotive vehicles are the high cost of carbon fiber and the need for an uninterrupted supply of large quantities of carbon fiber by the industry. An increase of 5- to 50-fold in worldwide carbon fiber production would be required to provide 10 to $100 \mathrm{~kg}$ for each of the 13 million cars and light trucks produced annually in the United States alone. ${ }^{4}$ To reduce the cost of production and to improve their environmental credentials, alternative fiber precursors from renewable feed stocks are being investigated.

Attempts to improve carbon fiber yield have been mainly limited to treatment involving the use of iodine. Recent research has reported that iodine acts as a stabilizing agent, resulting in a higher yield during fabrication of carbon fiber from coal tar pitch. Iodine retards oxidative depolymerization while promoting dehydrogenative polymerization during carbonization, leading to an extremely high carbon yield. Similarly, the carbon yield from polymers such as PAN and poly(vinyl alcohol) are increased considerably by carbonization with iodine. $^{7-9}$

It was also found that treatment of cellulosic fiber with sulfuric acid may increase the carbon yield by more than $300 \%{ }^{10}$ It is also known that sulfur species can destroy free-

\footnotetext{
Received: May 17, 2015

Revised: September 24, 2015
} 
radicals that are produced during carbonization and act to accelerate degradation of the fiber to carbon dioxide. ${ }^{11}$ The wool fiber has disulfide bonds that likely help in the quenching of the free-radical chain scission reaction during the pyrolysis of wool, thereby reducing carbon loss.

Mainly high purity $\mathrm{PAN}$ (acrylic), pitch, cellulose, regenerated cellulose, and lignin have been investigated as a carbon fiber precursor. The carbon content of PAN, lignin, wool, and cotton is $67.91,63.4,50$, and $44.4 \%$ respectively. ${ }^{12,13}$ Although the carbon content of wool is lower than the carbon content of lignin and polyacrylonitrile, it is rich in sulfur, which may cause lower carbon loss during pyrolysis providing higher carbon fiber yield than cotton, and its carbon content is also higher than cotton. Wool fibers are renewable, have good mechanical properties, and also are abundantly available at cheap prices. Although lignin has higher carbon content $(\sim 60 \%)$ compared to wool fiber, there is cost involved for the extraction of lignin from plants. Quality of lignin also varies not only species to species but also within plants, and also the extracted lignin will need to be converted to fiber by melt spinning (an energy intense process). A large quantity of wool fiber waste is produced all over the world every year, and their disposal is problematic because of their very slow biodegradability. The high value application of recycled wool will mitigate current waste disposal issues related to wool made carpets, apparels, and other products. Therefore, wool fiber could be a viable carbon fiber precursor compared to cellulosic fibers. Cellulosic fibers have been extensively investigated as a carbon fiber precursor, ${ }^{14,15}$ but until now no study has been carried out where wool fiber has been used as a carbon fiber precursor. Chen et al. produced activated carbon powder having high surface area by pyrolyzing wool fibers at $280{ }^{\circ} \mathrm{C}$ under nitrogen gas flow. ${ }^{16}$ It is known that cross-linking can improve the mechanical properties as well as thermal decomposition temperature of fibers and polymers, ${ }^{17-20}$ but their potential in increasing carbon yield has not been explored yet. In the present study, it is postulated that the introduction of crosslinks in wool fiber may improve the carbon fiber yield during the fabrication of carbon fiber from wool. For the first time, this work demonstrates the effect of cross-linking of wool fiber through the use of various ionic and covalent bond-forming agents on the carbon fiber yield and morphology.

\section{EXPERIMENTAL SECTION}

Materials. A plain-woven wool fabric of $270 \mathrm{~g} \mathrm{~m}^{-2}$ and having 12 ends $\mathrm{cm}^{-1}$ and 11 picks $\mathrm{cm}^{-1}$ made of recycled wool was used in this work. The wool fiber had a mean fiber diameter of $36 \mu \mathrm{m}$. Analytical reagent grade various ionic and covalent bond forming cross-linking agents such as succinic acid (SA1), sebacic acid (SA2), naphthalene disulfonic acid (NDS), itaconic anhydride (IA), succinic anhydride (SA3), and glyoxal (GO) were used as-received without further purification. All of the cross-linking agents investigated and acetic acid were purchased from Sigma-Aldrich Chemicals Ltd., USA. Sandozin MRN, a wetting agent, was purchased from Clariant Chemicals (Switzerland). Teric GN9, a nonionic surfactant, was purchased from Huntsman Chemicals (USA).

Cross-Linking of Wool Fibers. All of the cross-linking treatments of wool fiber were carried out by an exhaust method in an Ahiba Turbomat laboratory dyeing machine using a material to liquor ratio of 1:30. Typically, the bath was filled with water and dosed with $0.2 \mathrm{~g} \mathrm{~L}^{-1}$ Sandozin MRN (wetting agent) and $0.5 \mathrm{~mL} \mathrm{~L}^{-1}$ acetic acid. Table 1 shows the doses of various cross-linkers used to treat the wool fiber. The required quantity of a cross-linking agent was added and dissolved by mixing thoroughly. Wool fiber was introduced to the bath and the $\mathrm{pH}$ was adjusted to 3.0 with acetic acid and sodium acetate/sodium
Table 1. Chemical Treatment of Different Wool Samples

$\begin{array}{lccc}\begin{array}{c}\text { sample } \\ \text { ID }\end{array} & \begin{array}{c}\text { chemical } \\ \text { treatment }\end{array} & \begin{array}{c}\text { carbon yield } \\ (\%)^{a}\end{array} & \begin{array}{c}\text { standard deviation of carbon } \\ \text { yield }(\sigma)\end{array} \\ \text { Control } & & \begin{array}{c}16.70 \pm 1.35 \\ (\mathrm{a})\end{array} & 0.99 \\ \mathrm{~T} 1 & 6 \% \mathrm{SA} 1 & \begin{array}{c}21.10 \pm 1.42 \\ (\mathrm{~b})\end{array} & 1.02 \\ \mathrm{~T} 2 & 6 \% \mathrm{SA} 2 & \begin{array}{c}15.70 \pm 1.25 \\ (\mathrm{c})\end{array} & 0.95 \\ \mathrm{~T} 3 & 6 \% \mathrm{NDS} & \begin{array}{c}22.80 \pm 1.30 \\ (\mathrm{~d})\end{array} & 0.96 \\ \mathrm{~T} 4 & 2.5 \% \mathrm{IA} & \begin{array}{c}21.90 \pm 0.45 \\ (\mathrm{e})\end{array} & 0.69 \\ \mathrm{~T} 5 & 2.5 \% \mathrm{SA} 3 & \begin{array}{c}22.10 \pm 0.85 \\ (\mathrm{e})\end{array} & 0.57 \\ \mathrm{~T} 6 & 2.5 \% \mathrm{GO} & \begin{array}{c}19.16 \pm 0.75 \\ (\mathrm{f})\end{array} & 0.49\end{array}$

${ }^{a_{T}}$ Treatments that do not share a same letter are statistically significantly different at $5 \%$ level (two-sample $t$ test assuming unequal variances in Minitab 16).

hydroxide solution. The temperature was then increased to $70{ }^{\circ} \mathrm{C}$ at a rate of $2{ }^{\circ} \mathrm{C} \mathrm{min}{ }^{-1}$ and held for $30 \mathrm{~min}$. After completion of the exhaustion treatment, the bath was cooled to $45{ }^{\circ} \mathrm{C}$ at a rate of $2{ }^{\circ} \mathrm{C}$ $\mathrm{min}^{-1}$, after which the bath was drained and the samples were rinsed and dried at $60^{\circ} \mathrm{C}$ in an oven. The fibers were then stabilized under air at $160{ }^{\circ} \mathrm{C}$ in a curing oven for $10 \mathrm{~min}$. The treatments with SA3 and IA were carried out in a $500 \mathrm{~mL}$ round-bottomed flask at a $\mathrm{pH}$ of 9.0 that was adjusted with the addition of trimethylamine. After completion of the treatments, the samples were twice washed in distilled water to remove any unreacted chemicals. The mechanism of cross-linking of wool with various cross-linking agents is shown in Figure $1 .^{21,22}$

The add-on of various cross-linking agents to wool fiber was calculated for different doses of cross-linking agents and also at various $\mathrm{pH}$ values by subtracting the oven-dry weight of the sample before the treatment from the oven dry-weight of the sample after the treatment, divided by the value of the oven dry-weight of the sample before the treatment and expressed as a percentage. Samples were dried in an oven at $105 \pm 2{ }^{\circ} \mathrm{C}$ until such time that a constant sample weight was attained.

Thermogravimetric (TG) Analysis. An atmospheric pressure thermogravimetric analyzer (TGA) Model SDT Q600 made by TA Instruments (New Castle, USA) was used to study the pyrolysis behavior and carbon yield of untreated and various treated wool fibers. All TGA runs employed nitrogen (99.99\% pure and food-grade) as purge gas for the furnace with a constant flow rate of $100 \mathrm{~mL} \mathrm{~min}$. For each run, 7-10 mg of sample was loaded in a platinum pan. The untreated and various cross-linked wool fiber samples were heated to a pyrolysis temperature $\left(W_{\mathrm{b}}\right)$ of $800{ }^{\circ} \mathrm{C}$ at a rate of $10^{\circ} \mathrm{C} \mathrm{min}^{-1}$ under a constant nitrogen gas flow $\left(100 \mathrm{~mL} \mathrm{~min}{ }^{-1}\right)$. The sample was then held for a further $10 \mathrm{~min}$ at the pyrolysis temperature, and slowly cooled down to room temperature by switching off the furnace. The carbon yield was calculated by dividing the mass of the sample as measured at $W_{\mathrm{b}}$ by the dry mass measured at the end of the drying period at 105 ${ }^{\circ} \mathrm{C}\left(W_{\mathrm{a}}\right)$ according to eq 1 .

$$
\text { carbon yield }(\%)=\frac{W_{\mathrm{b}}}{W_{\mathrm{a}}} \times 100
$$

Characterization of Cross-Linked Wool Fiber. The characterization of wool fibers cross-linked with various cross-linking agents were carried out by attenuated total reflectance-Fourier transform infrared (ATR-FTIR) spectroscopy and also by measuring their tensile strength. It is anticipated that any cross-linking will increase the tensile strength of the cross-linked fibers. A PerkinElmer FTIR (Model: Spectrum 2000, PerkinElmer, Akron, USA) with an ATR attachment using zinc-selenium crystal was used for ATR-FTIR studies. For each sample, 64 scans were performed, and the average is reported here. The tensile strength of various cross-linked fibers was measured by an 


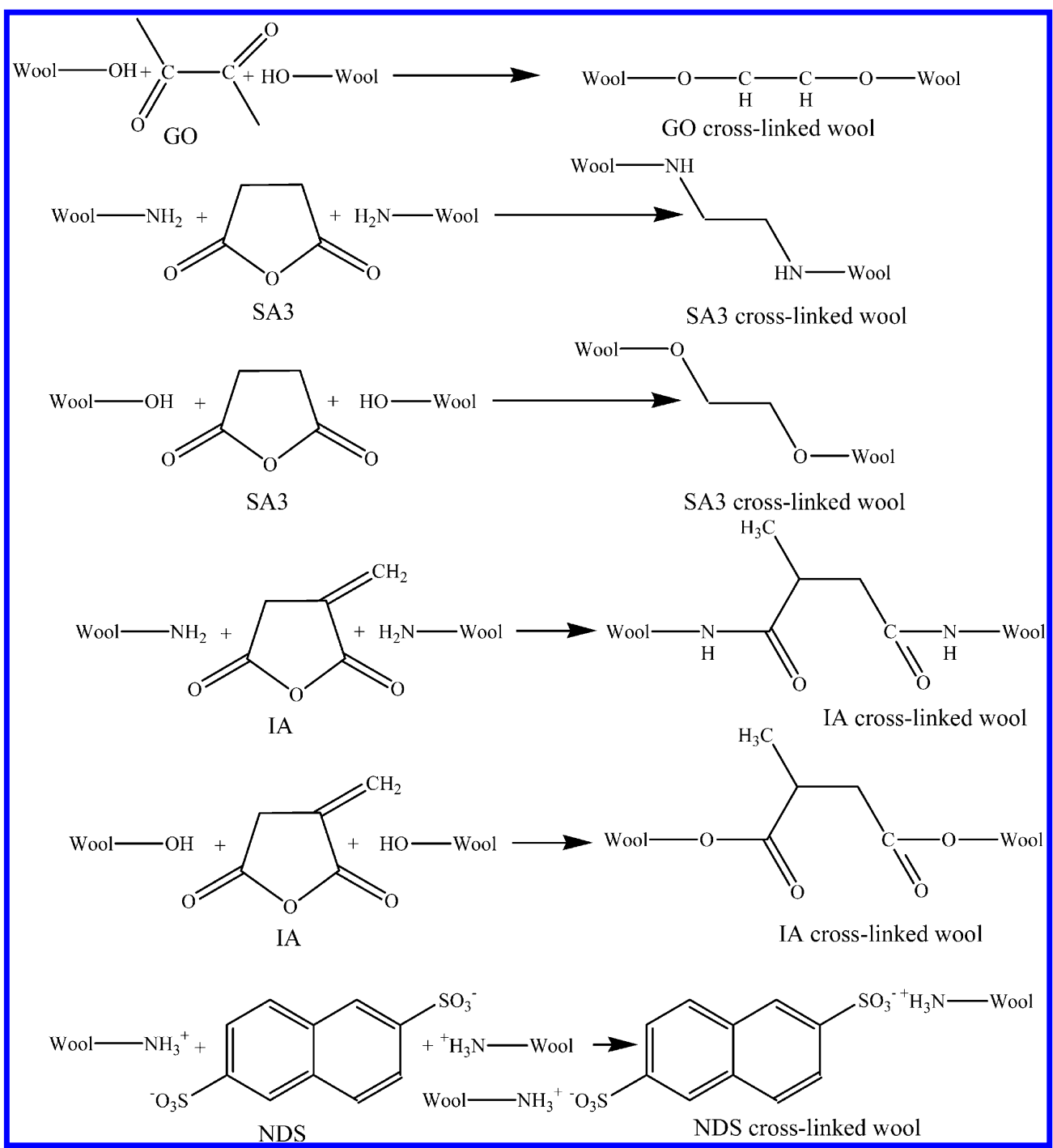

Figure 1. Reaction mechanism of wool fiber cross-linking with GO, SA3, IA, and NDS.

Instron Universal Testing Machine (Model 4204, Instron Inc. Norwood, USA). The gauge length was $10 \mathrm{~mm}$ and the cross-head speed was $2 \mathrm{~mm} \mathrm{~min}{ }^{-1}$. At least 10 fibers were measured for each treatment, and the average is reported here.

Carbonization. A temperature controlled horizontal tube furnace (High Temperature Vacuum Tube Furnace, Model OTF-1200X, MTI Corporation, Richmond, USA) was used to convert various crosslinked wool fibers to carbon fiber. All the samples were stabilized by heating under an oxygen environment at $160{ }^{\circ} \mathrm{C}$ for $10 \mathrm{~min}$ prior to pyrolysis. The wool fabric samples $(\sim 1 \mathrm{~g})$ were cut into pieces of a size of $125 \mathrm{~mm} \times 25 \mathrm{~mm}$ and were loaded into a crucible. Afterward, the crucible was placed in the furnace tube and the tube was purged with a constant flow of $100 \mathrm{~mL} \mathrm{~min}^{-1}$ nitrogen gas for $30 \mathrm{~min}$ before heating started as well as during heating. Each sample was heated to $200{ }^{\circ} \mathrm{C}$ at $2{ }^{\circ} \mathrm{C} \mathrm{min}^{-1}$ and held for $15 \mathrm{~min}$. The sample was then heated to 800 ${ }^{\circ} \mathrm{C}$ at $2{ }^{\circ} \mathrm{C} \mathrm{min}{ }^{-1}$ and held for $20 \mathrm{~min}$. After the reactor was cooled to room temperature at $5{ }^{\circ} \mathrm{C} \mathrm{min}-1$ under a constant flow of nitrogen $\left(100 \mathrm{~mL} \mathrm{~min}^{-1}\right)$, the produced carbon fiber sample was removed from the furnace and placed in a desiccator until various analyses were carried out.

Characterization of Carbon Fibers. Characterization of the produced carbon fibers were carried out in terms of chemical composition, carbon yield, surface topology, crystal structure, hydrophilicity, and tensile properties.

Mechanical Properties. The tensile strength at break and strain to failure were measured with an Instron Universal Testing Machine
(Model 4204, Instron Inc., Norwood, USA). Test specimens consisted of a single carbon fiber yarn with a gauge length of $10 \mathrm{~mm}$. Tensile testing was carried out at $20 \pm 2{ }^{\circ} \mathrm{C}$ and $65 \pm 2 \% \mathrm{RH}$ at a cross-head speed of $2 \mathrm{~mm} \mathrm{~min}^{-1}$ using a $10 \mathrm{~N}$ load cell. Specimens were mounted to a paper holder for testing using a cyanoacrylate adhesive. The average properties were reported based on at least 12 replicates. Statistical analysis of the data was carried out by two-sample $t$ test assuming unequal variances using Minitab Version 16 statistical software (Minitab, Inc., USA).

$X$-ray Diffraction. Carbon residues of selected samples were analyzed by using an X-ray diffractometer to determine crystal structure and crystallinity. Diffraction patterns of the samples were collected on a PW1820/1710 X-ray diffractometer (Phillips, Eindhoven, The Netherlands) using $\mathrm{Cu} \mathrm{K} \alpha$ radiation $(50 \mathrm{kV}, 40$ $\mathrm{mA})$. The samples were scanned over a $2 \theta$ range of $3-100^{\circ}$ in a stepscan using $0.02^{\circ}$ step $^{-1}$. The apparent crystallite thickness $\left(L_{c}\right)$, apparent layer-plain length parallel to the fiber axis $\left(L_{\mathrm{a}}\right)$, and average interlayer spacing $(d)$ were calculated using the following BraggScherrer formulas:

$$
\begin{aligned}
& d=\frac{\lambda}{2 \sin \theta} \\
& L=\frac{K \lambda}{\beta \cos \theta}
\end{aligned}
$$


where $\theta$ is the Bragg angle (deg), $\lambda$ is the wavelength of the X-rays ( $\lambda$ $=0.1541 \mathrm{~nm}$ ), $\beta$ is the half-height full width of the peak (radian), and $K$ is the form factor ( $K$ for $L_{c}$ and $L_{\mathrm{a}}$ is 0.89 and 1.84, respectively).

Fourier Transform Infrared Spectroscopy and Elemental Analysis. Untreated and various cross-linked wool fiber samples pyrolyzed at a temperature of $800{ }^{\circ} \mathrm{C}$ were analyzed with a PerkinElmer FTIR Spectrum 2000 spectrometer (PerkinElmer, Akron, USA). Ash-KBr mixtures were prepared by grinding, followed by pressing to produce discs for FTIR analysis in transmission. All spectra were averaged from 32 scans. Elemental analysis of carbon fiber produced from control and cross-linked wool fibers were carried out at Campbell Microanalytical Laboratory (University of Otago, New Zealand) to determine the levels of $\mathrm{C}, \mathrm{H}, \mathrm{N}$, and $\mathrm{S}$ content in the various carbon fibers.

Scanning Electron Microscopy (SEM). The surface and bulk microstructure of the as-produced carbon fiber were assessed by scanning electron microscopy. Carbonized samples were imaged using a JEOL JSM-6100 (JEOL, Tokyo, Japan) scanning electron microscope without any conductive coating, as the samples were conductive enough to prevent electrical discharge. SEM scanning of both cracked and longitudinal surfaces was carried out.

Contact Angle Measurement. The surface contact angle of various cross-linked wool fabrics that were carbonized at $800{ }^{\circ} \mathrm{C}$ was measured. The contact angle was measured in dynamic mode by using a KSV CAM 100 Contact Angle Measurement Apparatus (KSV Instruments Ltd., Finland). For each sample, the first measurement was taken immediately after the placement of a water droplet and then every $15 \mathrm{~s}$ up to a total contact time of $90 \mathrm{~s}$. The contact angle was measured in five different locations on each fabric to give an average value.

\section{RESULTS AND DISCUSSION}

Cross-Linking of Wool Fiber with Various CrossLinking Agents. The FTIR spectra of control wool fiber (blank-treated) and also wool fibers cross-linked with various cross-links are shown in Figure 2. The spectrum of wool fiber shows a peak at $1043 \mathrm{~cm}^{-1}$ for cysteic acid, $1626 \mathrm{~cm}^{-1}$ for amide I, $1531 \mathrm{~cm}^{-1}$ for amide II, and $1230 \mathrm{~cm}^{-1}$ for amide III. ${ }^{23}$ There is a broad peak at 3100 to $3400 \mathrm{~cm}^{-1}$, which could be attributed to the absorption band of hydroxyl groups. ${ }^{24}$ The spectrum of NDS-cross-linked wool fiber shows new peaks at $796,1029,1094,1174$, and $1260 \mathrm{~cm}^{-1}$, and these bands could be attributed to naphthalene, $-\mathrm{SO}_{3}$ functionalities of NDS, para substituted benzene and amide II, respectively. In the case of the spectra of wool fibers treated with aldehyde and anhydrides (IA and SA3), the intensity of the amide III band increased compared to the spectrum of control wool fiber, which indicates increased amide formation as succinic and itaconic anhydrides formed amide bonds with the amino groups of wool fiber. There is also a new absorption band at $1735 \mathrm{~cm}^{-1}$ in the case of wool fabrics treated with GO, SA3, and IA, which is associated with the absorption band of ester. The results achieved suggest that cross-linking agents not only reacted with the hydroxyl groups of wool keratin but also with the amino groups of wool.

Figure 3 shows the tensile strength of control wool fiber and also wool fiber treated with various cross-linking agents. It is evident that all the cross-linking treatments investigated increased the tensile strength of the treated wool fibers. Of the various cross-linking treatments investigated, the highest increase in tensile strength was observed for the wool fiber treated with SA3 and the lowest for the GO. The average tensile strength of control wool fiber was 103.8 MPA, which increased to 111.7, 115.2, 116.2, and $122 \mathrm{MPa}$ for the GO-, IA-, NDS-, and SA3-cross-linked wool fibers, respectively. The FTIR spectral analysis and the increase in tensile strength of the

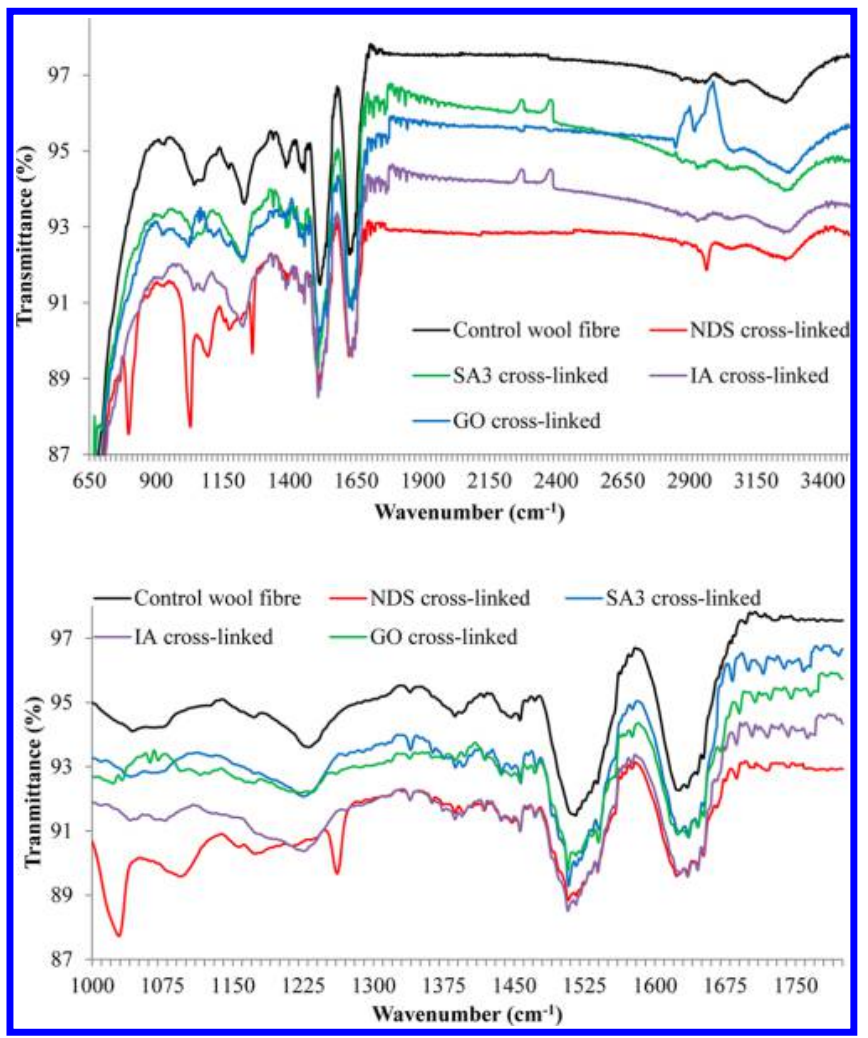

Figure 2. FTIR spectra of wool fiber cross-linked with NDS-, SA3-, IA-, and GO-cross-linked wool fibers. In the bottom panel, the spectra are enlarged from 1000 to $1800 \mathrm{~cm}^{-1}$.

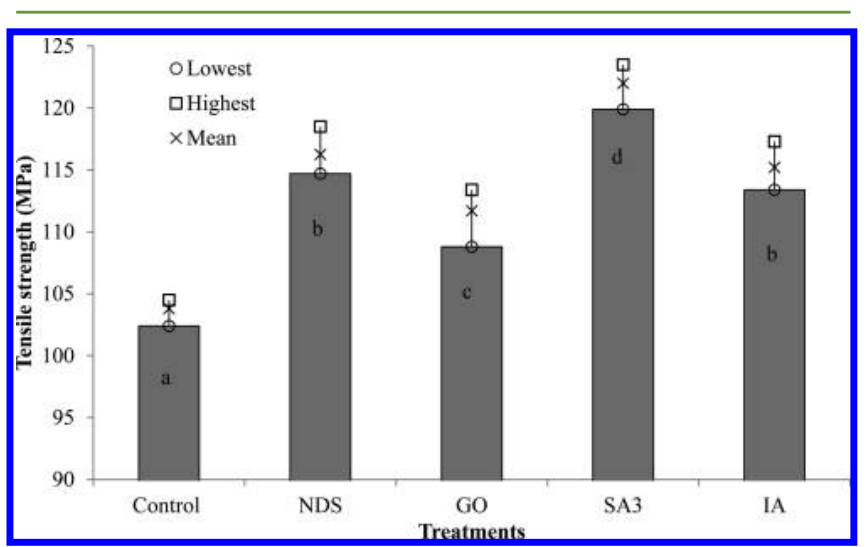

Figure 3. Tensile strength of control wool fiber and also wool fiber cross-linked with various cross-linking agents. Treatments that do not share a same letter are statistically significantly different at 5\% level (two-sample $t$ test assuming unequal variances in Minitab 16).

treated fibers after cross-linking suggest that wool fibers were successfully cross-linked by the cross-linking agents investigated in this work.

Carbonization Behavior of Wool Fiber. Figure 4a shows the thermogravimetric curves of wool fibers pretreated with various ionic and covalent bond forming cross-linking agents. The weight loss of wool was observed to mainly occur within three different temperature ranges: (i) 30-120, (ii) 220-400, and (iii) $400-800{ }^{\circ} \mathrm{C}$. The highest rate of weight loss occurs between 220 and $400{ }^{\circ} \mathrm{C}$. The first stage of weight loss (30$105^{\circ} \mathrm{C}$ ) accounted for $\sim 7-10 \%$ of the total weight loss due to loss of absorbed moisture. The second, and most significant, stage of weight loss $\left(220-400^{\circ} \mathrm{C}\right)$ accounted for a further loss 


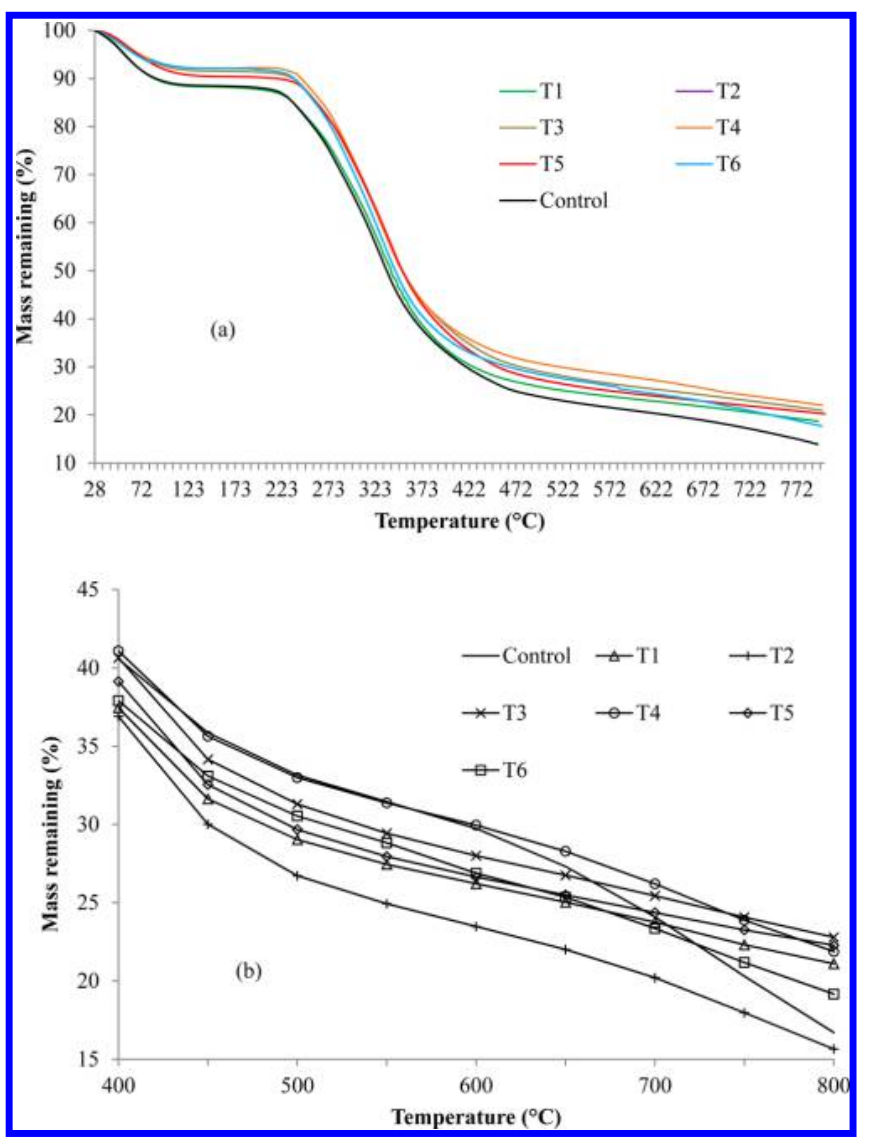

Figure 4. Weight loss (a) and carbon yield (b) of the untreated and treated wool fiber as a function of the temperature.

of $20-23 \%$ that is caused by the degradation of molecular structure of the wool fiber; the destruction of disulfide bonds and elimination of hydrogen sulfide gas are thought to be the primary cause. ${ }^{25}$ The $\alpha$-helix structure of wool is degraded during this process by the breakage of various chain linkages, peptide bridges, and some other lateral chains that ultimately lead to skeletal breakdown of the fiber. ${ }^{26}$ Generally, the weight loss of the variously pretreated wool fiber in the range of 20 to $550{ }^{\circ} \mathrm{C}$ was similar or higher compared to that observed for the untreated wool. Comparatively, the weight of the untreated wool fiber decreased rapidly at temperatures higher than 550 ${ }^{\circ} \mathrm{C}$. In contrast, the weight of the cross-linked fibers decreased relatively slowly. Generally, the carbon fiber yield of the variously cross-linked wool fibers was considerably higher compared to that of the untreated wool fiber; wool fibers treated with SA2 were the only exception. The weight loss reaches a plateau in the case of NDS- and SA3-treated wool fiber, whereas for other treated fibers the rate of weight loss continued to decrease. From Figure 4a, it can be seen that all of the treatments increased the thermal stability of wool between 600 and $800{ }^{\circ} \mathrm{C}$ compared with the untreated wool fiber. Of the cross-linking treatments investigated, NDS, SA3, and GO provided the highest thermal stability.

The results obtained indicate that cross-linked wool fibers produced thermally stable residues at $400-500{ }^{\circ} \mathrm{C}$ that decomposed slowly at higher temperatures compared to the untreated wool. Dehydrogenation takes place in the range of 400 to $600{ }^{\circ} \mathrm{C}$ for polyacrylonitrile, leading to the formation of graphite-like ribbons. At temperatures greater than $600{ }^{\circ} \mathrm{C}$, denitrogenation leads to the conversion of the ribbons formed at $400-500{ }^{\circ} \mathrm{C}$ into sheet-like structures. ${ }^{27-30}$

Carbon Fiber Yield as a Function of Cross-Linking

Treatment. Table 1 shows the carbon yield produced by the various cross-linked wool fibers at $800{ }^{\circ} \mathrm{C}$. The pyrolysis of the untreated wool at $800{ }^{\circ} \mathrm{C}$ resulted in a carbon yield of only $16.7 \%$. In contrast, all of the variously cross-linked wool fibers exhibited considerably higher carbon yields. The highest carbon yield achieved was $22.8 \%$ for the NDS at $6 \%$ oww, which is a $36 \%$ increase in carbon yield compared to that of the untreated wool fiber. Figure $4 \mathrm{~b}$ shows the effect of temperature on carbon fiber yield for the control and various cross-linked wool fibers carbonized at 400 to $800{ }^{\circ} \mathrm{C}$. The carbon yield decreases with increasing temperature because the degradation of wool fiber is also accompanied by an increased conversion of carbon to carbon dioxide at elevated temperatures. The untreated wool fiber showed similar or higher carbon fiber yield up to $550{ }^{\circ} \mathrm{C}$ compared to that of the cross-linked wool fibers. However, the situation is reversed at temperatures above $550{ }^{\circ} \mathrm{C}$ such that the carbon fiber yield increases for the cross-linked wool fibers. The SA2-treated wool exhibited a relatively poor carbon yield. SA2 has low solubility in water that may have affected its uptake by the wool fiber. Two anhydrides treated wool fibers showed similar (statistically insignificant) carbon yield but higher than the carbon yield achieved with SA1 and SA2. Of the crosslinking agents investigated, NDS was found to be the best cross-linking agent, as it at $6 \%$ level provided the highest carbon yield. Laufer et al. found that a thin coating of poly(vinyl sulfonic) acid on the order of a few nanometers in thickness improves the thermal stability and flame retardancy of a polyurethane foam. ${ }^{31}$ The presence of sulfur in poly(vinyl sulfonic) acid produces nonflammable sulfur dioxide gas at high temperatures, acting as a flame retardant. It is also known that sulfur species can destroy free-radicals produced during pyrolysis that otherwise accelerate the conversion of carbon fiber into carbon dioxide. ${ }^{32,33}$ In the case of NDS-cross-linked wool fiber, the presence of sulfur in the NDS cross-linking agent possibly reduced conversion of carbon of wool fiber into carbon dioxide by destroying free-radicals formed during carbonization, which increased the carbon fiber yield.

The optimization of cross-linking agents was carried out through their sorption study into wool fiber. NDS, SA1, and SA2 have affinity toward wool fiber, unlike to glyoxal and anhydrides as these do not have any affinity toward wool. We found that no benefit was observed beyond $2.5 \%$ oww application level for those cross-linking agents. Therefore, for these cross-linking agents, we limited their application to $2.5 \%$ oww. NDS, SA1, and SA2 showed similar trends in their sorption into wool, and therefore they were applied on wool at $6 \%$ oww level. As they showed a similar trend in sorption, optimization data for NDS are only shown here.

Sorption of NDS into Wool Fiber. The effect of adsorption of NDS as a function of the $\mathrm{pH}$ is shown in Figure 5. It is evident that an increase in $\mathrm{pH}$ decreases the sorption of NDS by wool fiber, with the lowest adsorption observed at $\mathrm{pH}$ 7. The highest uptake of NDS was achieved at a $\mathrm{pH}$ of 3 , while the lowest uptake was observed at a $\mathrm{pH}$ of 8 . The isoelectric point of wool in water is 4.5 , below which wool fiber is cationic and above it anionic. ${ }^{34} \mathrm{NDS}$ is an anionic compound similar to acid dyes without any chromophore and therefore is absorbed by wool at a $\mathrm{pH}$ below 5 , similar to the sorption of acid dyes by wool. The sorption of NDS by wool slowly decreased with an increase in the applied dosage of up to $6 \%$ NDS and almost 


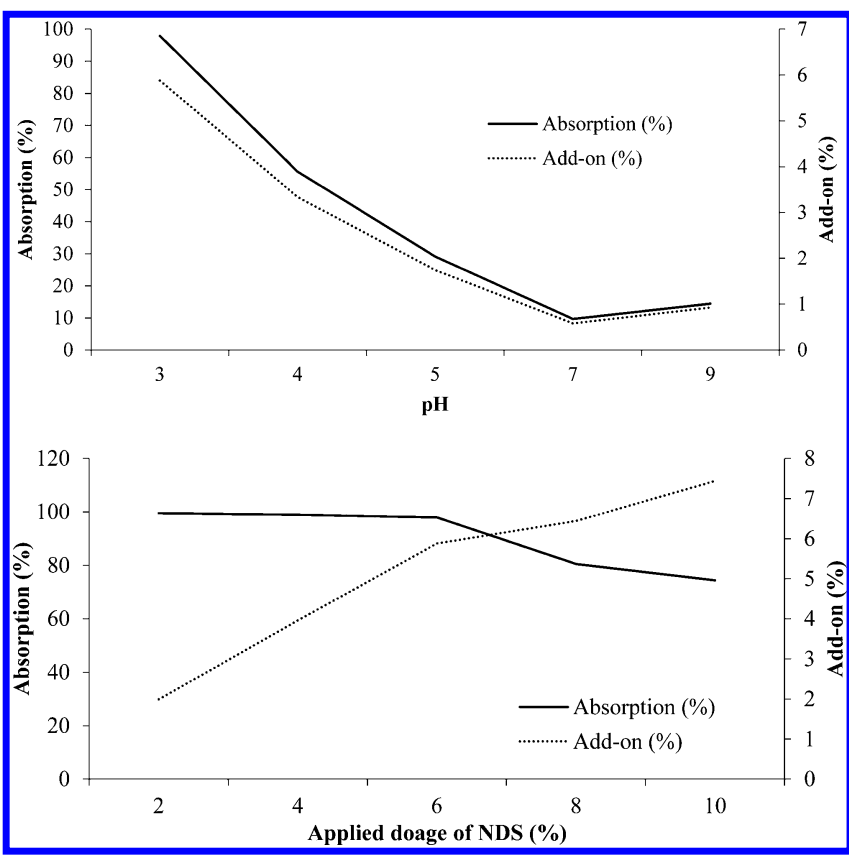

Figure 5. Effect of $\mathrm{pH}$ and applied dosage of NDS on the add-on and the absorption of NDS by wool fiber.

97-99\% sorption was achieved; after which the sorption level rapidly decreased with an increase in the applied dosage. Similarly, the add-on increased proportionally with an increase in the applied dosage of NDS up to $6 \%$ on the weight of wool (oww) of applied dosage after which the rate of increase in addon slowed down. An applied dosage of $6 \%$ is optimal because the sorption reaches a saturation level, with further increases in applied dosage providing no advantage. Therefore, $6 \%$ is the optimum cross-linking agent concentration for NDS.

The contact angle was measured to determine the hydrophilicity of the carbon fiber following the various cross-linking treatments. From contact angle data presented in Table 1 , it is evident that the surface of all of the carbon fibers produced from either untreated or cross-linked wool fibers exhibited superhydrophilicity. During the testing, the water droplet was absorbed immediately upon contacting the fiber surfaces such that it was impossible to measure a contact angle for any of the fibers. The surface of untreated wool fibers is usually strongly hydrophobic. Following carbonization, the resulting fibers were highly hydrophilic, indicating the formation of hydrophilic groups at the fiber surface.

Characterization of Wool-Derived Carbon Fiber. Structural Characteristics of Wool-Derived Carbon Fiber. WAXD was carried out on untreated and variously cross-linked wool fiber that had been carbonized at $800{ }^{\circ} \mathrm{C}$. From Figure 6a, it is evident that all of the various carbonized wool fibers produced a broad diffraction peak centered at $2 \theta=24.3^{\circ}$, indicative of the presence of an amorphous phase. ${ }^{35}$ All of the carbon fiber samples also exhibited a low, broad peak at $2 \theta=$ $44^{\circ}$ in their diffractograms that is assigned to the turbostratic band of disordered carbon (100). ${ }^{35}$ Although not as sharp as that of pure carbon, the observed diffraction peaks are direct evidence for the presence of carbon in all of the carbonized wool fiber samples examined in this work.

Table 2 shows the effect of various cross-linking treatments on the values of $d_{002}, d_{100}, L_{\mathcal{C}}$ and $L_{\mathrm{a}}$. The average value of the interlayer $d$-spacing of the graphitic basal planes of the

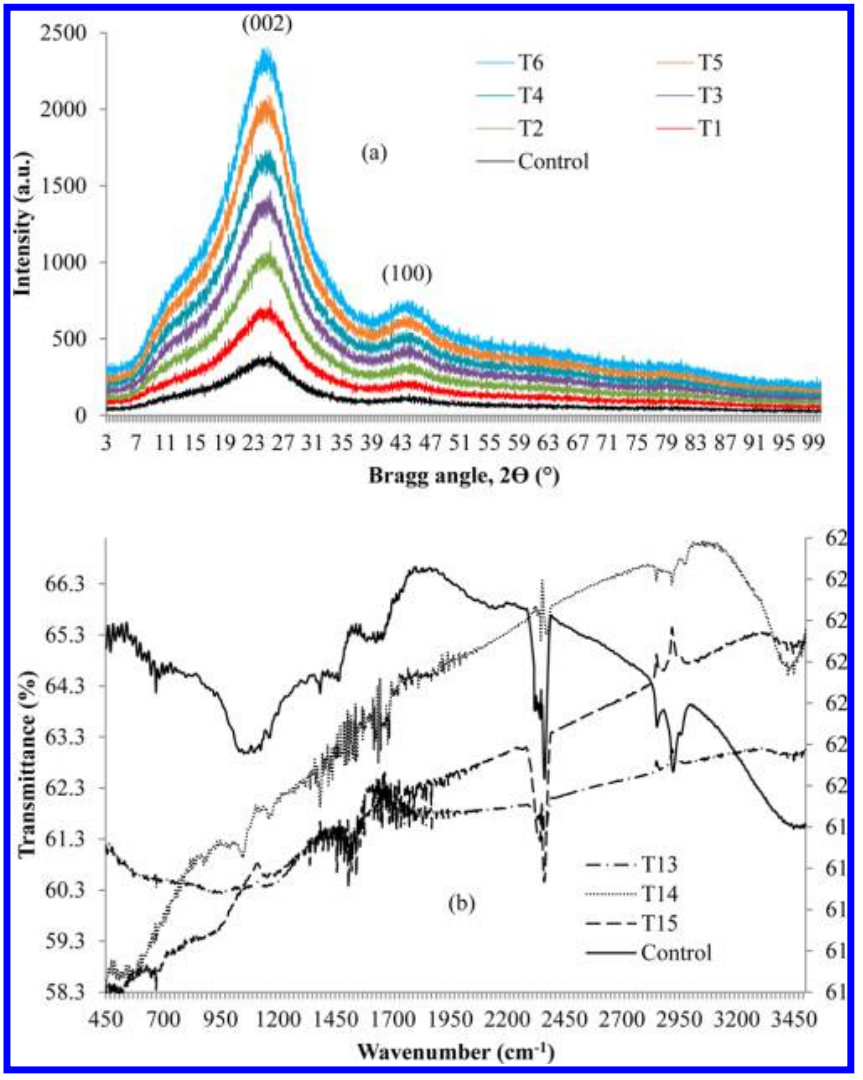

Figure 6. WAXD (a) and FTIR (b) spectra of untreated and variously cross-linked wool fibers that have been carbonized at $800{ }^{\circ} \mathrm{C}$.

Table 2. Structure Parameters of X-ray Diffraction for Fibers Produced from Various Pretreated Wool Fiber by Pyrolysis

\begin{tabular}{lccccc} 
treatment & $d_{(002)}(\mathrm{nm})$ & $d_{(100)}(\mathrm{nm})$ & $L_{\mathrm{c}}(\mathrm{nm})$ & $L_{\mathrm{c}} / d_{(002)}(\mathrm{nm})$ & $L_{\mathrm{a}}(\mathrm{nm})$ \\
Control & 0.3609 & 0.2242 & 0.9385 & 2.6007 & 1.9404 \\
T1 & 0.3801 & 0.2163 & 0.9142 & 2.4051 & 1.8902 \\
T2 & 0.3702 & 0.2206 & 1.0116 & 2.7325 & 2.0915 \\
T3 & 0.3710 & 0.2218 & 0.9683 & 2.6100 & 2.0019 \\
T4 & 0.3693 & 0.2307 & 0.9870 & 2.6726 & 2.0405 \\
T5 & 0.3745 & 0.2239 & 0.9622 & 2.5692 & 1.9891 \\
T6 & 0.3778 & 0.2239 & 0.9467 & 2.5059 & 1.9573 \\
\hline
\end{tabular}

untreated wool-derived carbon fiber, as obtained from the position of the (002) and (100) peaks, was 0.3646 and 0.2196 $\mathrm{nm}$, respectively, indicating the presence of nongraphitic carbon. Similar results are observed for carbon fiber produced from the cross-linked wool fiber. All of the cross-linking treatments increased the average interlayer spacing, such that $d_{002}$ increased from $0.3646 \mathrm{~nm}$ for the untreated wool fiber to a maximum of 0.3801 for $\mathrm{T} 1$.

Figure $6 \mathrm{~b}$ shows the FTIR spectra of carbon fiber derived from various cross-linked wool fibers. FTIR spectra of carbon fiber produced from untreated and cross-linked wool fiber exhibited a broad peak between 3200 and $3400 \mathrm{~cm}^{-1}$ that can be attributed to hydroxyl groups. ${ }^{24}$ The spectra of carbon fiber prepared from untreated wool fiber show two broad peaks at around 1100 and $1540 \mathrm{~cm}^{-1}$. The absorption peaks at 1100 and $1540 \mathrm{~cm}^{-1}$ can be attributed to stretching vibrations of $\mathrm{C}-$ $\mathrm{O}-\mathrm{C}$ and $\mathrm{C}=\mathrm{C}$ bonds, respectively, suggesting that the hydrophilicity of carbon fiber produced from untreated and cross-linked wool fiber is due to the presence hydroxyl and carboxyl groups. The surface hydrophilicity could be advanta- 
Table 3. Chemical Composition and Mechanical Properties of Carbon Fiber Produced from Various Cross-Linked Wool

\begin{tabular}{|c|c|c|c|c|c|c|c|c|}
\hline \multirow[b]{2}{*}{ treatments } & \multicolumn{4}{|c|}{ elements (\%) } & \multicolumn{4}{|c|}{ mechanical properties } \\
\hline & $\mathrm{C}$ & $\mathrm{H}$ & $\mathrm{N}$ & $S$ & tensile strength $(\mathrm{MPa})$ & standard deviation $(\sigma)$ & elongation at break (\%) & standard deviation $(\sigma)$ \\
\hline Control & 77.4 & 1.4 & 10.5 & 0.2 & $143.2 \pm 3.1\left(\mathrm{a}^{a}\right)$ & 2.53 & $0.4 \pm 0.15$ & 0.12 \\
\hline $\mathrm{T} 3$ & 79.9 & 1.2 & 10.4 & 0.3 & $165.3 \pm 5.3\left(b^{a}\right)$ & 4.00 & $0.4 \pm 0.12$ & 0.10 \\
\hline T5 & 80.8 & 1.3 & 10.3 & 0.3 & $160.1 \pm 3.5\left(c^{a}\right)$ & 2.82 & $0.5 \pm 0.21$ & 0.19 \\
\hline
\end{tabular}

${ }^{a}$ Treatments that do not share a same letter are statistically significantly different at $5 \%$ level (two-sample $t$ test assuming unequal variances in Minitab 16).

geous for the hydrophilic thermoplastic resin-based composites, as they will be compatible to each other.

Tensile Properties of Wool-Derived Carbon Fibers. The tensile strength of carbon fiber produced from high purity acrylic fiber is in the range of $850-5000 \mathrm{MPa}$. In contrast, the tensile strength and strain to failure of carbon fiber produced from untreated wool was $143.2 \mathrm{MPa}$ and $0.4 \%$, respectively (Table 1). The carbon fiber derived from the NDS-cross-linked wool fiber had the highest tensile strength $(165.3 \mathrm{MPa})$, which is a $55 \%$ increase compared to $103.8 \mathrm{MPa}$ of the untreated wool fiber. The tensile strength of the carbon fiber produced from cross-linked wool was low (160.1 to $165.3 \mathrm{MPa}$ ) compared to commercially available carbon fiber, but there is also demand in the market for these lower grade fibers for the application in thermoplastic composites. Clearly, the mechanical properties obtained suggest that there is potential for improving the process of manufacturing carbon fiber from wool fiber. The production of defect-free, low porosity carbon fiber is critical for maximizing the strength of carbon fiber. ${ }^{36}$ It will be through optimizing the processing conditions that the microstructure, and hence mechanical properties, of wool-derived carbon fiber will be improved.

Chemical Composition. Only the carbon fiber produced from the highest carbon yielding treated wool fibers (NDS and SA3) were considered for compositional analysis. The wool fiber precursor had $\mathrm{C}, \mathrm{H}, \mathrm{N}$, and $\mathrm{S}$ at 50.5, 6.80, 16.5, and 3.7 wt \%, respectively. Carbon fiber produced from NDS (T3) and SA3 (T5)-treated wool contained relatively high C contents, slightly higher $\mathrm{S}$ contents, and lower $\mathrm{H}$ and $\mathrm{N}$ contents compared to that from untreated wool fiber (Table 3). The observed changes in chemical composition tend to suggest a correlation between the tensile strength of the carbon fiber and its carbon content.

Surface Morphology and Contact Angle Measurement. The morphology of the as-produced and fractured carbon fiber from variously cross-linked wool fibers was investigated. The surface of wool fiber consists of scales that produce a rough exterior surface. Normally, wool fibers are cylindrical but after carbonizing they shrunk to almost $50 \%$ of the original diameter and became flat. Thus, the surface topology of carbon fiber produced from wool fiber might be expected to be also nonuniform. Numerous grooves were observed on the surface of the ribbon-shaped carbon fiber made from untreated and cross-linked wool fiber (Figure 7) and the surface of carbon fiber made from untreated wool fiber was observed to be wavy with grooves sizing from 100 to $500 \mathrm{~nm}$. In general, carbon fibers produced from all of the untreated and cross-linked wool fiber were nonporous; this is attributed to a slow heating rate that ensures minimal shrinkage and gradual release of the volatiles. A cross-sectional view in the transverse direction of the fracture surfaces of the fibers shows a lack of porosity in the bulk interior of the various carbon fibers. Thus, the grooves are only limited to the first few nanometers into the fiber surface

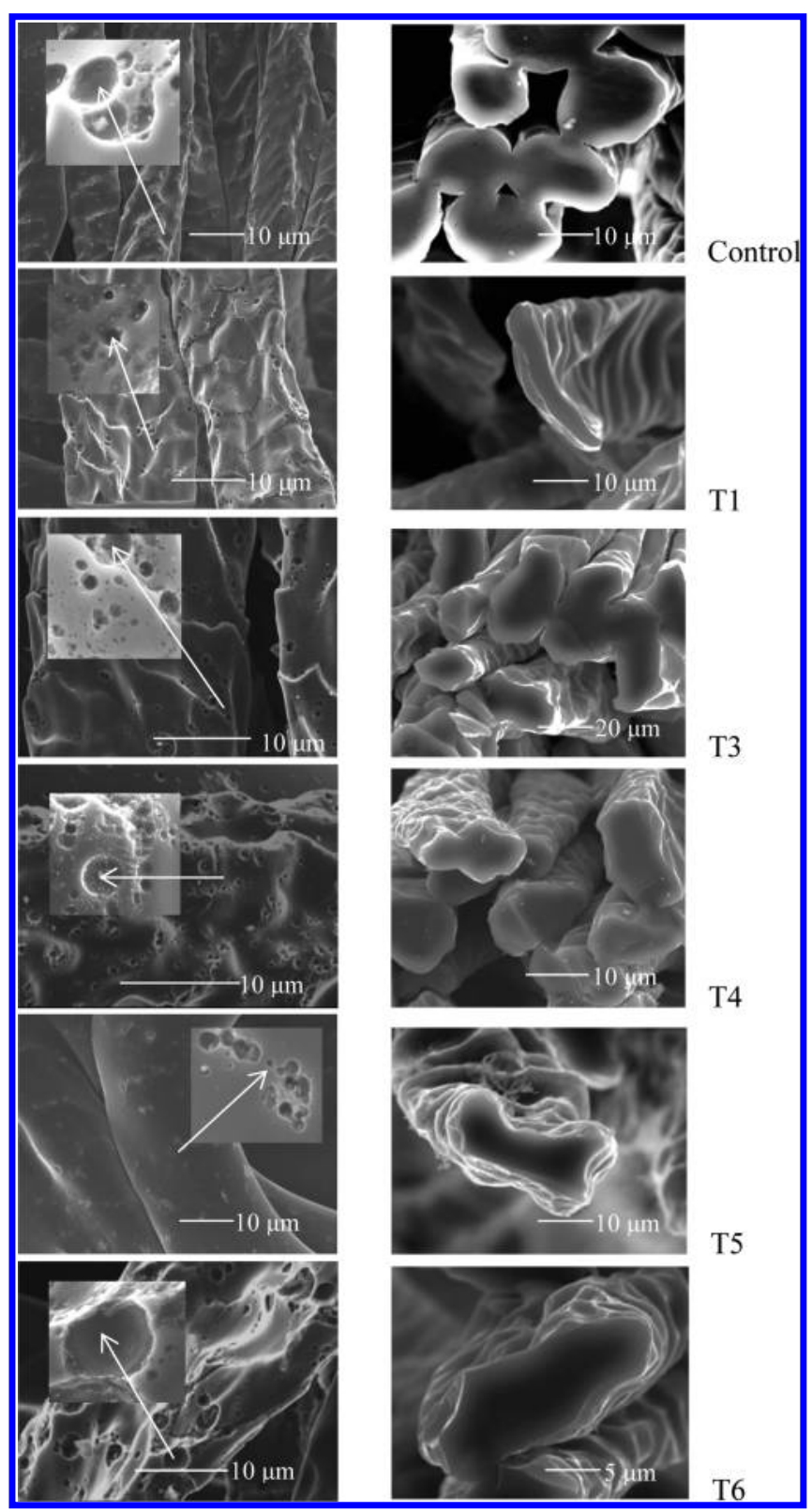

Figure 7. Scanning electron micrographs of the exterior surface (left) and the fractured surface of carbon fiber produced from untreated and variously pretreated wool fiber (inset: enlarged image).

(Figure 7). The grooved surface in the carbon fiber is advantageous in the case of composites manufacturing as thermoplastic resins can mechanically bind well to the surface of carbon fiber.

Sustainability of the Carbon Fiber Production from Wool. In terms of carbon footprint, acrylic fiber, which is a synthetic fiber, has higher footprint compared to the natural 
wool fiber. Barber and Pellow ${ }^{37}$ estimated that the production of acrylic fiber consumes $175 \mathrm{MJ} \mathrm{kg}^{-1}$ energy, whereas wool consumes only $63 \mathrm{MJ} \mathrm{kg}^{-1}$ energy. If we assume that the carbon fiber production from wool fiber and acrylic fiber consumes the same energy as the carbon fiber production process for both the precursors are identical, then there is a huge difference in greenhouse gas emission for the carbon fiber produced from the both precursor fibers. By using United States Environmental Protection Agency's “Greenhouse Gas Equivalencies Calculator", we estimated that the greenhouse gas emission for acrylic fiber production is $33.5 \mathrm{~kg} \mathrm{CO}_{2} \mathrm{~kg}^{-1}$ but for wool fiber it is only $12.1 \mathrm{~kg} \mathrm{CO}_{2} \mathrm{~kg}^{-1}$, which is almost one-third of the greenhouse gas emission observed for acrylic fiber production. Therefore, we can conclude that the carbon fiber production from wool is more sustainable compared to the production of carbon fiber from acrylic fiber.

\section{CONCLUSIONS}

It was found in this work that carbon fibers are able to be produced through the carbonization of untreated and crosslinked wool fiber. The carbon yield of the resulting fibers was found to be a function of the type of cross-linking agents applied to the wool fiber, although more detailed studies are required to understand the mechanisms involved. The surface topology of the resulting carbon fiber was similar regardless of the type of cross-linking treatment used. Cross-linking was found to improve the tensile strength of the carbon fiber when compared to that from untreated wool fiber. It was found that wool-derived carbon fiber was strongly hydrophilic, and this appears to be due to the increase in hydrophilic groups introduced to the surface of carbon fiber. Wool fiber could be a sustainable and renewable carbon fiber precursor and this high value application of waste wool will also mitigate current disposal problems of wool waste, thereby improving our environment.

\section{AUTHOR INFORMATION}

\section{Corresponding Author}

*M. M. Hassan. Email: mahbubul.hassan@agresearch.co.nz.

\section{Author Contributions}

The paper was written through contributions of all authors. All authors have given approval to the final version of the paper. Mohammad M. Hassan and Linda Schiermeister contributed equally to this work.

\section{Funding}

The authors gratefully acknowledge financial assistance from AgResearch Ltd., through the AgResearch Curiosity Fund (Contract No. A19526).

\section{Notes}

The authors declare no competing financial interest.

\section{ACKNOWLEDGMENTS}

The authors thank Matthew Polson and Vladimir Golovko (Department of Chemistry) for assistance with carbonization and TGA experiments. The authors also thank Mike Flaws (Department of Mechanical Engineering), Stephen Brown (Geological Sciences), and Chikako van Koten (AgResearch) for assistance with SEM, WAXD, and statistical analysis, respectively.

\section{REFERENCES}

(1) Barrero, A.; Bedia, J.; Cordero, T.; Lallave, M.; Loscertales, I. G.; Rodriguez-Mirasol, J.; Ruiz-Rosas, R. The production of submicron diameter carbon fibers by the electro-spinning of lignin. Carbon 2010, $48,696-705$.

(2) Alway-Cooper, R. M.; Anderson, D. P.; Ogale, A. A. Carbon black modification of mesophase pitch-based carbon fibers. Carbon 2013, 59, $40-48$.

(3) Hirose, T.; Fujino, T.; Fan, T.; Endo, H.; Okabe, T.; Yoshimura, M. Effect of Carbonization temperature on the structural changes of wood-ceramics impregnated with liquefied wood. Carbon 2002, 40, 761-765.

(4) Compere, A. L.; Griffith, W. L.; Leitten, C. F., Jr; Shaffer, J. T. Low cost carbon fiber from renewable resources. SAE Tech. Pap. Ser. 2001, 33, 1306-1314.

(5) Kajiura, H.; Tanabe, Y.; Yasuda, E. Carbonization and graphitization behaviors of iodine treated coal tar pitch. Carbon 1997, 35, 169-174.

(6) Miyajima, N.; Akatsu, T.; Ikoma, T.; Ito, O.; Rand, B.; Tanabe, Y. A role of charge transfer complex with iodine in the modification of coal tar pitch. Carbon 2000, 38, 1831-1838.

(7) Khan, M. M. R.; Gotoh, Y.; Morikawa, H.; Miura, M.; Fujimori, Y.; Nagura, M. Carbon fiber from natural biopolymer Bombyx mori silk fibroin with iodine treatment. Carbon 2007, 45, 1035-1042.

(8) Fatema, U. K.; Tomizawa, C.; Harada, M.; Gotoh, Y. Iodine-aided fabrication of hollow carbon fibers from solid poly(vinyl alcohol) fibers. Carbon 2011, 49, 2158-2161.

(9) Chen, J. C.; Harrison, I. R. Modification of polyacrylonitrile (PAN) carbon fiber precursor via post-spinning plasticization and stretching in dimethyl formamide (DMF). Carbon 2002, 40, 25-45.

(10) Kim, D. Y.; Nishiyama, Y.; Wada, M.; Kuga, S. High-yield carbonization of cellulose by sulfuric acid impregnation. Cellulose 2001, 8, 29-33.

(11) Beach, M. W.; Rondan, N. G.; Froese, R. D.; Gerhart, B. B.; Green, J. G.; Stobby, B. G.; Shmakov, A. G.; Shvartsberg, V. M.; Korobeinichev, O. P. Studies of degradation enhancement of polystyrene by flame retardant additives. Polym. Degrad. Stab. 2008, 93, 1664-1673.

(12) Hassan, M. M.; McLaughlin, J. R. Formation of poly(methyl methacrylate) thin films onto wool fiber surfaces by vapor deposition polymerization. ACS Appl. Mater. Interfaces 2013, 5, 1548-1555.

(13) Park, S.-J.; Heo, G.-Y. Precursors and manufacturing of carbon fibers. In: Carbon Fibers; Park, S.-J., Ed.; Springer-Verlag: Berlin, 2015; p 32.

(14) Dumanli, A. G.; Windle, A. H. Carbon fibers from cellulosic precursors: a review. I. Mater. Sci. 2012, 47, 4236-4250.

(15) Kong, K.; Deng, L.; Kinloch, I. A.; Young, R. J.; Eichhorn, S. J. Production of carbon fibers from a pyrolyzed and graphitized liquid crystalline cellulose fiber precursor. I. Mater. Sci. 2012, 47, 5402-5410.

(16) Chen, W.; Liu, X.; He, R. L.; Lin, T.; Zeng, Q. F.; Wang, X. G. Activated carbon powders from wool fibers. Powder Technol. 2013, 234, 76-83.

(17) Miles, C. A.; Avery, N. C.; Rodin, V. V.; Bailey, A. J. The increase in denaturation temperature following crosslinking in collagen

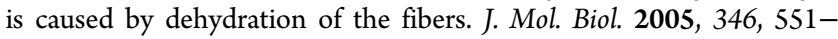
556.

(18) Lomakin, S. M.; Brown, J. E.; Breese, R. S.; Nyden, M. R. An investigation of thermal stability and char forming tendency of crosslinked poly(methyl methacrylate). Polym. Degrad. Stab. 1993, 41, 229-243.

(19) Uhl, F. M.; Levchik, G. F.; Dick, C.; Liggat, J.; Snape, C. E.; Wilkie, C. A. The thermal stability of crosslinked polymers: methyl methacrylate with divinylbenzene and styrene with dimethacrylates. Polvm. Degrad. Stab. 2001, 71, 317-325.

(20) Ma, W.; Zhao, C.; Yang, J.; Ni, J.; Wang, S.; Zhang, N.; Lin, H.; Wang, J.; Zhang, G.; Li, Q.; Na, H. Crosslinked aromatic cationic polymer electrolytes with enhanced stability for high temperature fuel cell applications. Energy Environ. Sci. 2012, 5, 7617-7625. 
(21) Zhang, Y.; Zhu, P. C.; Edgren, D. Crosslinking reaction of poly(vinyl alcohol) with glyoxal. I. Polvm. Res. 2010, 17, 725-730.

(22) Girek, T.; Ciesielski, W. Polymerization of b-cyclodextrin with succinic anhydride and thermogravimetric study of the polymers. $J$. Inclusion Phenom. Mol. Recognit. Chem. 2011, 69, 439-444.

(23) Singh, B. R. Basic aspects of the technique and applications of infrared spectroscopy of peptides and proteins. In Infrared Analysis of Peptides and Proteins Principles and Applications; Singh, B. R., Ed.; Vol. 750; ACS Symposium Series; American Chemical Society: Washington, DC, 2000.

(24) Hassan, M. M. Enhanced antistatic and mechanical properties of corona plasma treated wool fabrics treated with 2,3-epoxypropyltrimethylammonium chloride. Ind. Eng. Chem. Res. 2014, 53, 1095410964.

(25) Manefee, E.; Yee, L. Thermally-induced structural changes in wool. Text. Res. I. 1965, 35, 801-812.

(26) Popescu, C.; Augustin, P. Effect of chlorination treatment on the thermo-gravimetric behavior of wool fibers. J. Therm. Anal. Calorim. 1999, 57, 509-515.

(27) Hassan, M. M.; Schiermeister, L.; Staiger, M. P. Thermal, chemical and morphological properties of carbon fibres derived from chemically pre-treated wool fibers. RSC $A d v$. 2015, 5, 55353-55362.

(28) Senoz, E.; Wool, R. P.; McChalicher, C. J. M.; Hong, C. K. Physical and chemical changes in feather keratin during pyrolysis. Polvm. Degrad. Stab. 2012, 97, 297-304.

(29) Goodhew, P. J.; Clarke, A. J.; Bailey, J. E. A review of the fabrication and properties of carbon fibers. Mater. Sci. Eng. 1975, 17, 3-30.

(30) Huang, X. Fabrication and properties of carbon fibers. Materials 2009, 2, 2369-2403.

(31) Laufer, G.; Kirkland, C.; Morgan, A. B.; Grunlan, J. C. Exceptionally flame retardant sulfur-based multilayer nanocoating for polyurethane prepared from aqueous polyelectrolyte solutions. ACS Macro Lett. 2013, 2, 361-365.

(32) Zachariah, M. R.; Smith, O. I. Experimental and numerical studies of sulfur chemistry in $\mathrm{H}_{2} / \mathrm{O}_{2} / \mathrm{Ar}$ flames. Combust. Flame 1987, 69, 125-139.

(33) Beach, M. W.; Rondan, N. G.; Froese, R. D.; Gerhart, B. B.; Green, J. G.; Stobby, B. G.; Shmakov, A. G.; Shvartsberg, V. M.; Korobeinichev, O. P. Studies of degradation enhancement of polystyrene by flame retardant additives. Polym. Degrad. Stab. 2008, 93, 1664-1673.

(34) Sookne, A. M.; Harris, M. Electrophoretic studies of wool. Text. Res. J. 1939, 9, 437-444.

(35) Srinivas, G.; Zhu, Y.; Piner, R.; Skipper, N.; Ellerby, M.; Ruoff, R. Synthesis of graphene-like nanosheets and their hydrogen absorption capacity. Carbon 2010, 48, 630-635.

(36) Huson, M. G.; Church, J. S.; Kafi, A. A.; Woodhead, A. L.; Khoo, J.; Kiran, M. S. R. N.; Bradby, J. E.; Fox, B. L. Heterogeneity in carbon fiber. Carbon 2014, 68, 240-249.

(37) Barber, A.; Pellow, G. LCA: New Zealand merino wool total energy use. 5th Australian Life Cycle Assessment Society (ALCAS) Conference, Melbourne, November 22-24, 2006. 